\title{
An Investigation of the Oxygen Pathways in the Oxidative Coupling of Methane over MgO-Based Catalysts
}

\author{
E. P. J. Mallens, J. H. B. J. Hoebink, and G. B. Marin ${ }^{1}$ \\ Schuit Institute of Catalysis, Laboratorium voor Chemische Technologie, Eindhoven University of Technology, \\ P.O. Box 513, 5600 MB Eindhoven, The Netherlands
}

Received May 24, 1995; revised October 26, 1995; accepted December 28, 1995

\begin{abstract}
The oxidative coupling of methane to ethane and ethene has been investigated by admitting pulses of pure methane, pure oxygen, and mixtures of methane and oxygen to $\mathrm{MgO}, \mathrm{Li} / \mathrm{MgO}$, and $\mathrm{Sn} / \mathrm{Li} / \mathrm{MgO}$ at temperatures ranging from 923 to $1073 \mathrm{~K}$ in a Temporal Analysis of Products (TAP) set-up. Moreover, pulses of oxygen followed by pulses of either methane, ethane, ethene, or carbon monoxide were applied to study the role of both adsorbed oxygen and surface lattice oxygen in the reaction mechanism. Two types of reversibly adsorbed oxygen are present on $\mathrm{Sn} / \mathrm{Li} / \mathrm{MgO}$. The first type is strongly adsorbed oxygen, which desorbs from the surface on a time scale of $3 \mathrm{~min}$ at $973 \mathrm{~K}$. This type of oxygen does not seem to be reactive toward methane. The second type of oxygen consists of weakly adsorbed oxygen species with a time scale of desorption amounting to $4 \mathrm{~s}$ at $973 \mathrm{~K}$. The weakly adsorbed oxygen species are involved in the direct conversion of methane to carbon dioxide. Surface lattice oxygen is also interacting with the admitted reductants. The percentage of surface lattice oxygen reactive in the methane conversion is less than $0.1 \%$ of a theoretical monolayer on $\mathrm{MgO}$ at $1023 \mathrm{~K}$. This value amounts to $27 \%$ for $\mathrm{Li} / \mathrm{MgO}$ and $44 \%$ for $\mathrm{Sn} / \mathrm{Li} / \mathrm{MgO}$ at the same temperature. On $\mathrm{Li} / \mathrm{MgO}$ and $\mathrm{Sn} / \mathrm{Li} / \mathrm{MgO}$ two different types of surface lattice oxygen are present. The first is active in methyl radical formation, while the second is involved in the direct conversion of methane to carbon dioxide. Weakly adsorbed oxygen and the second type of surface lattice oxygen are also involved in the nonselective reaction paths of ethane and ethene as well as in the consecutive oxidation of carbon monoxide. Strongly adsorbed oxygen is not involved in these reactions. The observations are consistent with the Lunsford mechanism [Ito, T., Wang, J.-X., Lin, C.-H., and Lunsford, J. H., J. Am. Chem. Soc. 107, 5062 (1985)] for the generation of methyl radicals over MgO-based catalysts. The increasing activity toward methane due to the addition of lithium and moreover tin to $\mathrm{MgO}$ can be explained by an increase in the amount of reactive surface lattice oxygen.

(C) 1996 Academic Press, Inc.
\end{abstract}

\section{INTRODUCTION}

The oxidative coupling of methane aims at the production of ethane and ethene, abbreviated as $\mathrm{C}_{2}$ products, at temperatures between 900 and $1200 \mathrm{~K}$ and pressures between 100 and $1000 \mathrm{kPa}$.

\footnotetext{
${ }^{1}$ To whom correspondence should be addressed.
}

Keller and Bhasin (1) were among the first to report formation of $\mathrm{C}_{2}$ products when feeding in an alternating way methane and air to metal oxides supported on $\gamma-\mathrm{Al}_{2} \mathrm{O}_{3}$. Production of $\mathrm{C}_{2}$ products was reported for a supported lead oxide catalyst by Hinsen and Baerns (2) as well as for $\mathrm{Li} / \mathrm{MgO}$ by Ito and Lunsford (3) when cofeeding methane and oxygen.

In the oxidative coupling of methane the production of methyl radicals proceeds via methane activation at the catalyst surface (4-7). Nonselective reactions are catalysed by the surface as well, leading to the formation of $\mathrm{CO}_{x}$. The active sites for methyl radical formation in the case of $\mathrm{Li} /$ $\mathrm{MgO}$ are considered to be $\mathrm{Li}^{+} \mathrm{O}^{-}$centers, as identified by electron paramagnetic resonance (EPR) $(3,4,8,9)$, or $\mathrm{O}^{-}$ ions which are in equilibrium with these centers (10). The $\mathrm{Li}^{+} \mathrm{O}^{-}$centers are formed by the substitution of $\mathrm{Li}$ for $\mathrm{Mg}$ in the $\mathrm{MgO}$ lattice which is possible since the respective ionic radii of $\mathrm{Li}^{+}$and $\mathrm{Mg}^{2+}$ are nearly equivalent. Besides $\mathrm{O}^{-}$anions also other reactive forms of oxygen were mentioned in the oxidative coupling of methane, e.g., the superoxide anion $\mathrm{O}_{2}^{-}(11,12)$, the oxide anion $\mathrm{O}^{2-}(13-15)$, the peroxide anion $\mathrm{O}_{2}^{2-}(16-19)$, and the ozonide anion $\mathrm{O}_{3}^{-}(11)$.

The oxidative coupling over $\mathrm{MgO}$ and $\mathrm{Li} / \mathrm{MgO}$ (20-22) and $\mathrm{Sn} / \mathrm{Li} / \mathrm{MgO}$ (22) was studied using steady-state isotopic transient kinetic analysis. It was concluded that oxygen interacts strongly with the surface by dissociative reversible adsorption. Both surface and bulk lattice oxygen participate in the reaction. The promotion with lithium and even more with tin increases the mobility of oxygen in the bulk and the amount of exchangeable oxygen per unit BET surface area. Cant et al. (23) studied the rates of oxygen isotope exchange processes over $\mathrm{Li} / \mathrm{MgO}$ using ${ }^{16} \mathrm{O}_{2} /{ }^{18} \mathrm{O}_{2}$ mixtures at temperatures of $973 \mathrm{~K}$ up to $1023 \mathrm{~K}$. It was concluded that the exchange occurs via oxygen present as $\mathrm{Li}_{2} \mathrm{O}$, which also is likely to be involved in the activation of methane. An increase in the exchange between gas phase and lattice oxygen is also reported for Sr-promoted $\mathrm{La}_{2} \mathrm{O}_{3}(24,25)$. The mobility of lattice oxygen increases and oxygen vacancies are created in the structure of $\mathrm{La}_{2} \mathrm{O}_{3}$. Buyevskaya et al. (26) studied the interaction of oxygen with catalytic surfaces of $\mathrm{MgO}, \mathrm{Sm}_{2} \mathrm{O}_{3}(5 \%) / \mathrm{MgO}$, and $\mathrm{Sm}_{2} \mathrm{O}_{3}$, with the 
oxygen exchange increasing in this order. The presence of methane did not influence the exchange rate.

The reactivity of adsorbed versus lattice oxygen is also a point of interest. Buyevskaya et al. (27) reported that surface lattice oxygen of pure $\mathrm{MgO}$ is responsible for methyl radical formation resulting in $\mathrm{C}_{2}$ products, while adsorbed oxygen species take part in the total oxidation reactions. Two different active sites for the formation of $\mathrm{C}_{2}$ products and carbon oxides were reported on $\mathrm{Sm}_{2} \mathrm{O}_{3}, \mathrm{Li} / \mathrm{Sm}_{2} \mathrm{O}_{3}$, and $\mathrm{Pr}_{6} \mathrm{O}_{11}$ (28), $\mathrm{Li} / \mathrm{MgO}(20,21)$, and $\mathrm{PbO} / \mathrm{MgO}$ (32), whereas parallel paths for selective and nonselective reactions are also reported by other authors for $\mathrm{Li} / \mathrm{MgO}(22,29-31)$. However, in the case of $\operatorname{Pr}_{6} \mathrm{O}_{11}$ lattice oxygen catalyzes the direct conversion of methane to carbon dioxide (28). The activity of $\mathrm{Li} / \mathrm{NiO}$ was mainly related to lattice oxygen, which catalyzes the selective reactions, while adsorbed oxygen promotes full oxidation (33). The lattice oxygen may be considered as a $\mathrm{Li}-\mathrm{Ni}$ oxide phase. For $\mathrm{Li} / \mathrm{TiO}_{2}$ a large pool of oxygen species participating in the formation of carbon dioxide was reported, while subsurface lattice oxygen species also participate in the oxygen reaction pathway to form carbon dioxide (34).

The objective of the present study was to investigate the interaction of oxygen with $\mathrm{MgO}, \mathrm{Li} / \mathrm{MgO}$, and $\mathrm{Sn} / \mathrm{Li} / \mathrm{MgO}$ by means of pulse experiments. The reactivity of both adsorbed and surface lattice oxygen was studied as well. A mechanism for the reaction pathways of oxygen during the oxidative coupling of methane over $\mathrm{MgO}$-based catalysts is postulated.

\section{EXPERIMENTAL}

\section{Materials}

The gases used were methane (99.9995\%), ethane (99.95\%), ethene (99.95\%), carbon monoxide (99.9997\%), oxygen (99.995\%), and argon (99.99995\%) from Air Products. Labeled oxygen, ${ }^{18} \mathrm{O}_{2}$ (99\%), from Union Carbide was used in the oxygen exchange experiments.

The catalysts used in this investigation were $\mathrm{MgO}$, lithium-promoted $\mathrm{MgO}$, and tin/lithium-promoted $\mathrm{MgO}$. The catalysts were essentially prepared as described by Korf et al. (35). The BET surface area, elemental composition, and grain size of the fresh catalysts are presented in Table 1. Nonporous $\alpha-\mathrm{Al}_{2} \mathrm{O}_{3}$ with a grain size of 0.21 to $0.25 \mathrm{~mm}$ was used as inert packing material.

\section{Equipment and Procedures}

A Temporal Analysis of Products (TAP) setup was applied, which has been described in detail elsewhere (36). The microreactor of the TAP setup can be considered as a batchwise operated fixed bed reactor with a typical residence time of $100 \mathrm{~ms}$. Mass spectrometry is used to follow the outlet responses toward pulses of reactants admitted at the inlet with a submillisecond time resolution. It allows one
TABLE 1

BET Surface Area, Elemental Composition, and Grain Size of Fresh $\mathrm{MgO}, \mathrm{Li} / \mathrm{MgO}$, and $\mathrm{Sn} / \mathrm{Li} / \mathrm{MgO}$

\begin{tabular}{lccc}
\hline & $\mathrm{MgO}$ & $\mathrm{Li} / \mathrm{MgO}$ & $\mathrm{Sn} / \mathrm{Li} / \mathrm{MgO}$ \\
\hline BET surface area $\left(\mathrm{m}^{2} \mathrm{~g}^{-1}\right)$ & $25.6 \pm 0.7$ & $0.6 \pm 0.3$ & $2.1 \pm 0.3$ \\
$\mathrm{Li}(\mathrm{wt} \%)$ & - & 3.7 & 4.6 \\
$\mathrm{Sn}(\mathrm{wt} \%)$ & - & - & 3.2 \\
$\mathrm{Mg}(\mathrm{wt} \%)$ & 54.0 & 53.0 & 47.0 \\
Grain size $(\mathrm{mm})$ & $0.15-0.21$ & $0.21-0.30$ & $0.21-0.25$ \\
\hline
\end{tabular}

to study catalytic sequences in detail, even at a high conversion. A limited number of molecules is admitted to the catalyst surface leading to information about the reactants and products at a well defined state of the surface.

The shape of a response is determined by the various processes occurring in the microreactor, namely Knudsen diffusion, adsorption, desorption, and reaction. Each response has a unique rise time, peak maximum, and decay curve.

A plot of the responses as a function of time contains in principle information on the reaction network. A secondary product has a response with a larger rise time than a primary product and its peak maximum is observed later. Adsorption and desorption processes result in a shift of the peak maximum toward a larger time value. The position of the peak maximum is also determined by the molecular weight of the component via the Knudsen diffusion coefficient.

The continuous flow mode of operation of the microreactor was applied for the pretreatment of the catalyst and determination of the absolute calibration factors. The latter allows one to convert the mass spectrometer signal into moles per second.

Three different types of transient experiments were performed. The first one is referred to as a pulse experiment, during which the response to a single pulse is measured at a fixed atomic mass unit (amu) value.

The second type is an alternating pulse experiment, also called a pump-probe experiment (36). Two single pulses are introduced and the response is monitored at a fixed amu value. The time interval between the two single pulses may be varied by the user and leads in principle to information on the lifetime and reactivity of adsorbed species, which are created during the first single pulse and probed with a suitable reactant during the second single pulse.

In both a pulse and an alternating pulse experiment pulses are repeated regularly and the responses are averaged to improve the signal-to-noise ratio. The repetition time is sufficiently large to avoid accumulation of adsorbed species at the surface.

The third type concerns a multipulse experiment. A series of single pulses is introduced and the responses of all pulses are monitored separately, i.e., without signal averaging, at a fixed amu value. The time interval between two 
single pulses is variable and must be larger than the average residence time in the reactor. During a multipulse experiment the interaction of a component with the surface is studied at different degrees of surface coverage.

The number of molecules admitted per single pulse was in the range of $10^{16}-10^{17}$, resulting in an average total pressure of $1000 \mathrm{~Pa}$ above the catalyst surface during $100 \mathrm{~ms}$. In a single pulse the ratio of admitted methane as well as oxygen molecules to the theoretical number of surface oxygen atoms was always below 0.03 .

The inconel microreactor, with a length of $42 \mathrm{~mm}$ and an inner diameter of $6 \mathrm{~mm}$, was charged with 0.1 to $0.4 \mathrm{~g}$ of catalyst and packed with inert material at each end. Two thermocouples were inserted into the catalyst bed for temperature measurements. The axial temperature difference over the bed was always limited to $5 \mathrm{~K}$.

Blank pulse experiments of methane as well as methane with oxygen over $\alpha-\mathrm{Al}_{2} \mathrm{O}_{3}$ showed a conversion of $2 \%$, which is negligible compared to conversions obtained in the presence of a catalyst. In all experiments argon was added to the admitted gases as a reference component for calculation of the conversion of the reactants and the amount of admitted molecules.

The catalyst was pretreated in situ at a temperature of $1073 \mathrm{~K}$ with a flow of oxygen amounting to $10^{-6} \mathrm{~mol} / \mathrm{s}$. In case of $\mathrm{Li} / \mathrm{MgO}$ and $\mathrm{Sn} / \mathrm{Li} / \mathrm{MgO}$ carbon dioxide desorption was observed during the pretreatment. In order to ensure a reproducible state of the catalyst the pretreatment continued until the desorption of carbon dioxide was negligible, which took $8 \mathrm{~h}$ for the largest catalyst loading. Furthermore, prior to each experiment the catalyst was exposed to oxygen for $5 \mathrm{~min}$, after which adsorbed oxygen was removed by maintaining a vacuum of $10^{-5}$ Pa for $5 \mathrm{~min}$.

The experiments were carried out in the temperature range of 923 to $1073 \mathrm{~K}$. Only ethane and carbon monoxide were observed during the interaction of methane or methane and oxygen with the surface. No formation of ethene was observed. In case of $\mathrm{Li} / \mathrm{MgO}$ and $\mathrm{Sn} / \mathrm{Li} / \mathrm{MgO}$ it was not possible to detect carbon dioxide quantitatively at the reactor outlet due to its strong adsorption on the catalyst surface. Pulse experiments with carbon dioxide showed no breakthrough up to a temperature of $973 \mathrm{~K}$. Therefore carbon dioxide formation was deduced from the carbon balance, although methyl radicals could not be accounted for quantitatively. Only in the case of $\mathrm{MgO}$ can carbon dioxide be detected quantitatively. In the case of pulse experiments with labeled oxygen the mass balance was closed within $7 \%$.

For each experiment the conversion and yields were calculated according to the equations

$$
\begin{gathered}
X_{\mathrm{CH}_{4}}=\frac{n_{\mathrm{in}, \mathrm{CH}_{4}}-n_{\mathrm{out}, \mathrm{CH}_{4}}}{n_{\mathrm{in}, \mathrm{CH}_{4}}}, \\
Y_{\mathrm{C}_{2} \mathrm{H}_{6}}=\frac{2 n_{\mathrm{out}, \mathrm{C}_{2} \mathrm{H}_{6}}}{n_{\mathrm{in}, \mathrm{CH}_{4}}},
\end{gathered}
$$

$$
\begin{aligned}
& Y_{\mathrm{CO}}=\frac{n_{\mathrm{out}, \mathrm{CO}}}{n_{\mathrm{in}, \mathrm{CH}_{4}}}, \\
& Y_{\mathrm{CO}_{2}}=\frac{n_{\mathrm{in}, \mathrm{CH}_{4}}-n_{\mathrm{out}, \mathrm{CH}_{4}}-n_{\text {out }, \mathrm{CO}}-2 n_{\mathrm{out}, \mathrm{C}_{2} \mathrm{H}_{6}}}{n_{\mathrm{in}, \mathrm{CH}_{4}}}, \\
& X_{{ }^{18} \mathrm{O}_{2}}=\frac{n_{\mathrm{in},{ }^{18} \mathrm{O}_{2}}-n_{\text {out },{ }^{18} \mathrm{O}_{2}}}{n_{\mathrm{in},{ }^{18} \mathrm{O}_{2}}},
\end{aligned}
$$

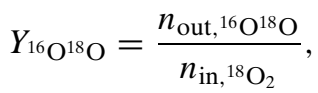

$$
\begin{aligned}
& Y_{16} \mathrm{O}_{2}=\frac{n_{\text {out },{ }^{16} \mathrm{O}_{2}}}{n_{\text {in, }{ }^{18} \mathrm{O}_{2}}}
\end{aligned}
$$

where $n$ is the total number of moles, $X$ is the conversion, and $Y$ is the yield. The subscript "in" means introduced into the reactor and the subscript "out" means detected at the reactor outlet.

Activation energies were derived from the observed linear dependence of $\ln X$ on the inverse temperature, applying an identical amount of molecules per pulse at various temperatures. Only measurements with a conversion lower than $50 \%$ were selected for determination of the activation energies.

\section{RESULTS}

\section{Interaction of Oxygen with the Surface}

The interaction of oxygen with the catalytic surfaces was investigated with multipulse experiments of oxygen, with a 4-s time interval between the pulses. The exchange between gaseous oxygen and surface lattice oxygen was studied on $\mathrm{MgO}$ and $\mathrm{Sn} / \mathrm{Li} / \mathrm{MgO}$ with pulse experiments of labeled oxygen, ${ }^{18} \mathrm{O}_{2}$.

$\mathrm{Sn} / \mathrm{Li} / \mathrm{MgO}$. The responses of a multipulse experiment at $923 \mathrm{~K}$ are shown in Fig. 1. The surface area of the individual oxygen responses initially increases and finally remains constant. The initial increase is attributed to oxygen interacting strongly with the catalyst surface. This strongly adsorbed oxygen desorbs completely on a time scale of $3 \mathrm{~min}$ at $973 \mathrm{~K}$.

All individual responses of oxygen are broadened when compared to argon, as shown in Fig. 2, which points to a second type of oxygen species interacting with the catalyst surface. This type is referred to as weakly adsorbed oxygen and the time interval required for complete desorption amounts to $4 \mathrm{~s}$ at $973 \mathrm{~K}$.

The amount of strongly adsorbed oxygen, expressed as a percentage of the theoretical number of surface oxygen atoms, is presented in Table 2 , based on $1.26 \times 10^{19}$ oxygen atoms per square meter. The amount increases with increasing temperature. The activation energy for the interaction of oxygen via the strongly adsorbed oxygen species amounts to $35 \mathrm{~kJ} \mathrm{~mol}^{-1}$, as derived from the first pulse of the multipulse experiment.

The interaction of oxygen with the surface via the weakly adsorbed species was further investigated by pulse 


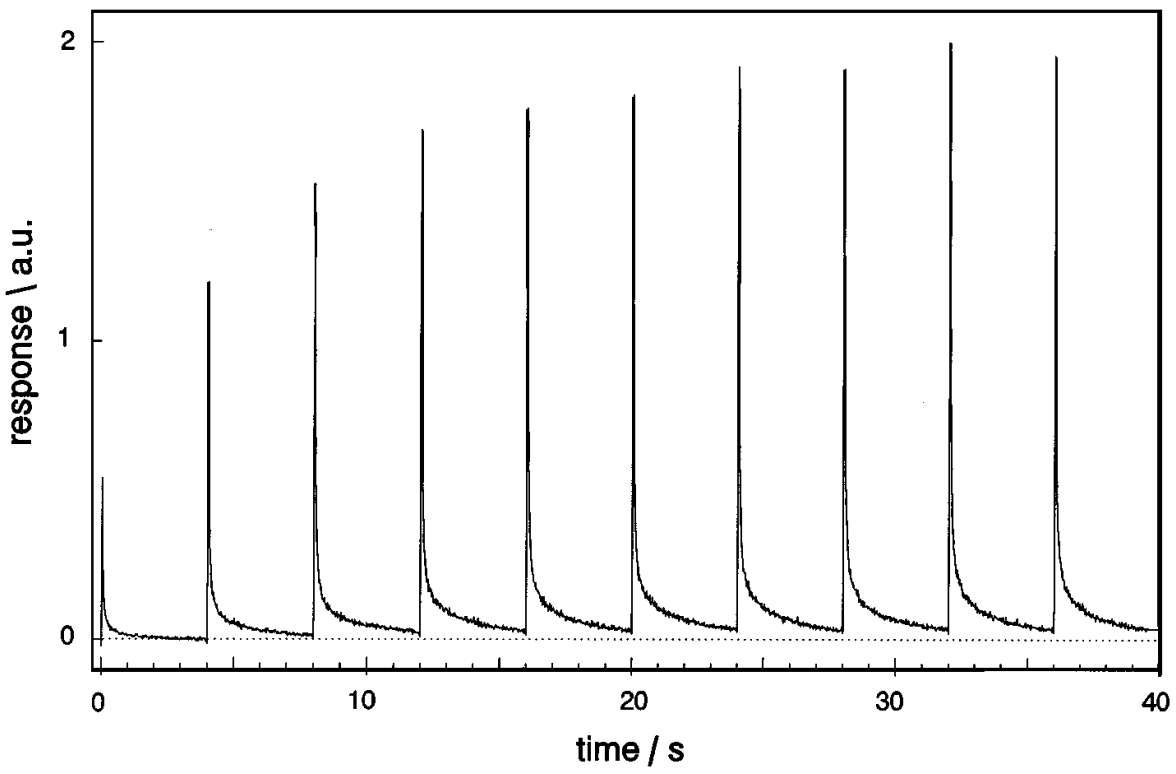

FIG. 1. Response of oxygen as a function of time at $923 \mathrm{~K}$. Multipulse experiment of oxygen over $0.11 \mathrm{~g}$ of $\mathrm{Sn} / \mathrm{Li} / \mathrm{MgO}$ with a pulse intensity of $5 \times 10^{16}$ molecules.

experiments of labeled oxygen. Prior to each experiment 10 single pulses of labeled oxygen were introduced in order to reach the maximum concentration of strongly adsorbed oxygen, which is necessary for closed oxygen balances.

During the interaction of labeled oxygen with the surface the exchange products ${ }^{16} \mathrm{O}^{18} \mathrm{O}$ as well as ${ }^{16} \mathrm{O}_{2}$ were produced. The normalized responses of ${ }^{18} \mathrm{O}_{2},{ }^{16} \mathrm{O}^{18} \mathrm{O}$, and ${ }^{16} \mathrm{O}_{2}$ at a temperature of $773 \mathrm{~K}$ are shown in Fig. 3. The response of ${ }^{18} \mathrm{O}_{2}$ is observed first, followed by that of ${ }^{16} \mathrm{O}^{18} \mathrm{O}$ and finally ${ }^{16} \mathrm{O}_{2}$.
The conversion of ${ }^{18} \mathrm{O}_{2}$ increases from $40 \%$ at $773 \mathrm{~K}$ to $90 \%$ at $923 \mathrm{~K}$. The yield of ${ }^{16} \mathrm{O}^{18} \mathrm{O}$ shows a maximum of $50 \%$, while that of ${ }^{16} \mathrm{O}_{2}$ increases from 10 to $42 \%$. The activation energy for the interaction of oxygen via the weakly adsorbed species amounts to $35 \mathrm{~kJ} \mathrm{~mol}^{-1}$.

$\mathrm{Li} / \mathrm{MgO}$. The results of a multipulse experiment are qualitatively identical to those obtained on $\mathrm{Sn} / \mathrm{Li} / \mathrm{MgO}$. The surface area of the oxygen responses increases and finally remains constant, pointing to a first type of oxygen

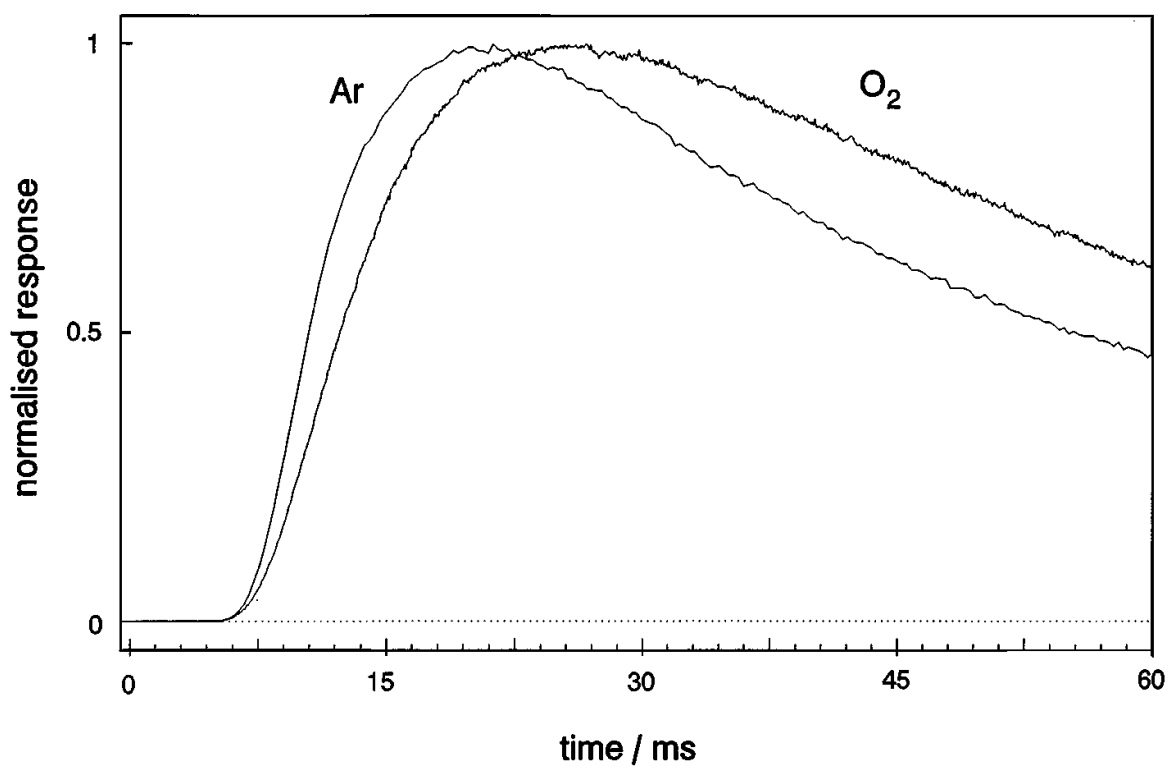

FIG. 2. Normalized responses of oxygen and argon as a function of time at $973 \mathrm{~K}$. Pulse experiment of oxygen and argon over $0.11 \mathrm{~g}$ of Sn/Li/ $\mathrm{MgO}$ with a pulse intensity of $5 \times 10^{16}$ molecules. Ten pulses were introduced prior to the experiment. 
TABLE 2

Amount of Strongly Adsorbed Oxygen, Expressed as a Percentage of a Theoretical Monolayer, Present on $0.35 \mathrm{~g}$ of $\mathrm{Li} / \mathrm{MgO}$ and $0.11 \mathrm{~g}$ of $\mathrm{Sn} / \mathrm{Li} / \mathrm{MgO}$ at Various Temperatures Ranging from 923 to $1023 \mathrm{~K}$, as Obtained from Multipulse Experiments of Oxygen with a Pulse Intensity of $5 \times 10^{16}$ Molecules

\begin{tabular}{rcc}
\hline $\mathrm{T}(\mathrm{K})$ & $\mathrm{Li} / \mathrm{MgO}(\%)$ & $\mathrm{Sn} / \mathrm{Li} / \mathrm{MgO}(\%)$ \\
\hline 923 & 5.1 & 4.7 \\
948 & 6.3 & 6.3 \\
973 & 8.1 & 6.9 \\
998 & 10.2 & 9.1 \\
1023 & 11.5 & 10.6 \\
\hline
\end{tabular}

species interacting strongly with the surface. It desorbs completely on a time scale of $3 \mathrm{~min}$ at $973 \mathrm{~K}$.

The amount of strongly adsorbed oxygen is also presented in Table 2 and is similar to that of $\mathrm{Sn} / \mathrm{Li} / \mathrm{MgO}$ when expressed per unit BET surface area. However, the activation energy for the interaction of oxygen with the surface via strongly adsorbed oxygen amounts to $92 \mathrm{~kJ}$ $\mathrm{mol}^{-1}$, which is significantly higher compared to the value obtained for $\mathrm{Sn} / \mathrm{Li} / \mathrm{MgO}$.

All responses are broadened with respect to argon, pointing to weakly adsorbed oxygen species on the surface, which desorb on a time scale of $3 \mathrm{~s}$ at $973 \mathrm{~K}$.

$\mathrm{MgO}$. An immediate and complete breakthrough of oxygen was observed in a multipulse experiment with oxygen, which means that oxygen species showing a strong interaction with the surface are not present.
Weakly adsorbed oxygen species are present, as concluded from the peak broadening compared to argon, which was further investigated with labeled oxygen experiments. Again, the response of ${ }^{18} \mathrm{O}_{2}$ is observed first, followed by that of ${ }^{16} \mathrm{O}^{18} \mathrm{O}$ and ${ }^{16} \mathrm{O}_{2}$. The conversion of labeled oxygen increases from $10 \%$ at $773 \mathrm{~K}$ to $77 \%$ at $923 \mathrm{~K}$. The corresponding yields to ${ }^{16} \mathrm{O}^{18} \mathrm{O}$ and ${ }^{16} \mathrm{O}_{2}$ increase from 8 and $2 \%$ to 53 and $24 \%$.

Weakly adsorbed oxygen desorbs on a time scale of $0.5 \mathrm{~s}$ at $923 \mathrm{~K}$ and the activation energy for the interaction of oxygen with the surface amounts to $120 \mathrm{~kJ} \mathrm{~mol}^{-1}$.

\section{Reactivity of Adsorbed Oxygen Species}

The reactivity of adsorbed oxygen species was investigated with alternating pulse experiments, pulsing first oxygen and next either methane, ethane, ethene, or carbon monoxide at an admitted molar ratio of 2 to 3 in order to ensure a complete reoxidation of the catalyst. In case of $\mathrm{Sn} / \mathrm{Li} / \mathrm{MgO}$ no oxygen breakthrough was observed.

$\mathrm{Sn} / \mathrm{Li} / \mathrm{MgO}$. Seven different time intervals were applied between the oxygen and the methane pulses, varying from zero, i.e., simultaneous pulsing, up to $10 \mathrm{~s}$. The experiments were carried out at a temperature of $973 \mathrm{~K}$. The conversion of methane decreases from 60 to $44 \%$ with increasing time interval due to the disappearance of weakly adsorbed oxygen species, having a time scale for desorption of $4 \mathrm{~s}$ at $973 \mathrm{~K}$. However, the yield of ethane and carbon monoxide remain constant at varying time intervals at 0.45 and $0.11 \%$, meaning that weakly adsorbed oxygen only contributes to methane conversion into carbon dioxide.

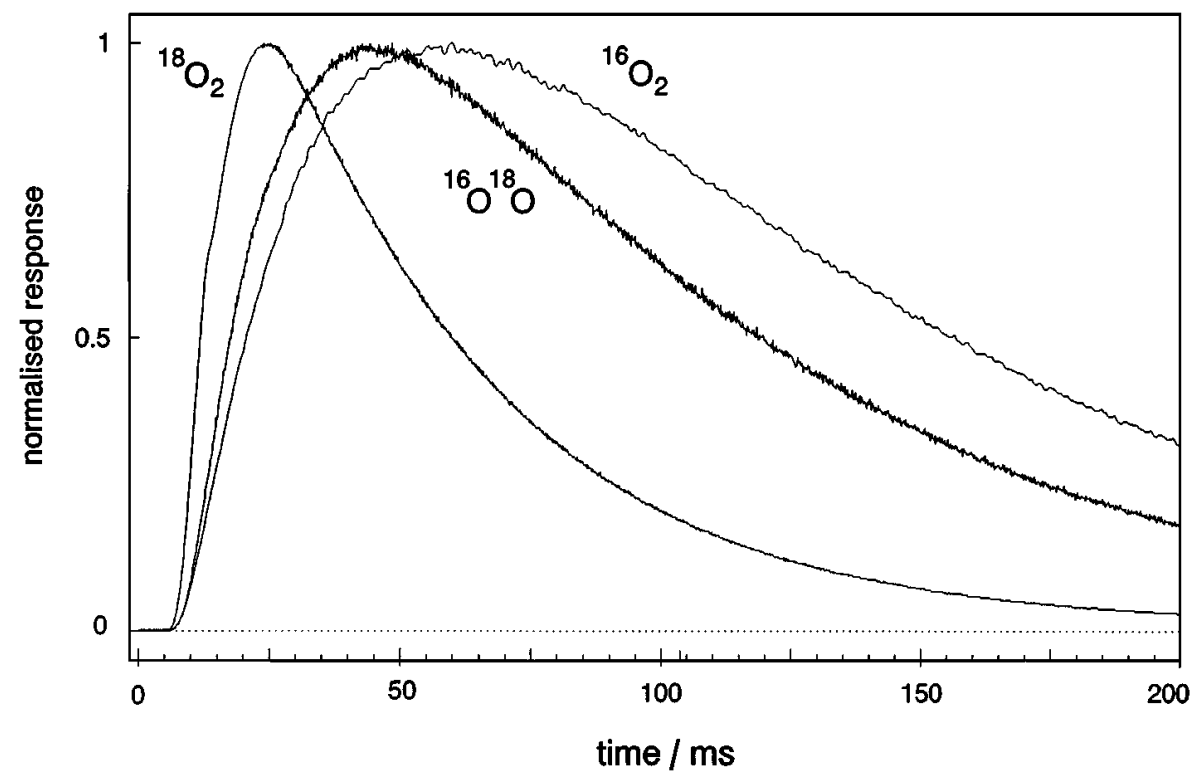

FIG. 3. Normalized responses of ${ }^{18} \mathrm{O}_{2},{ }^{16} \mathrm{O}^{18} \mathrm{O}$, and ${ }^{16} \mathrm{O}_{2}$ as a function of time at a temperature of $773 \mathrm{~K}$. Pulse experiment of labeled oxygen over $0.10 \mathrm{~g} \mathrm{Sn} / \mathrm{Li} / \mathrm{MgO}$ with a pulse intensity of $5 \times 10^{16}$ molecules. Ten pulses of labeled oxygen were introduced prior to the experiment. 


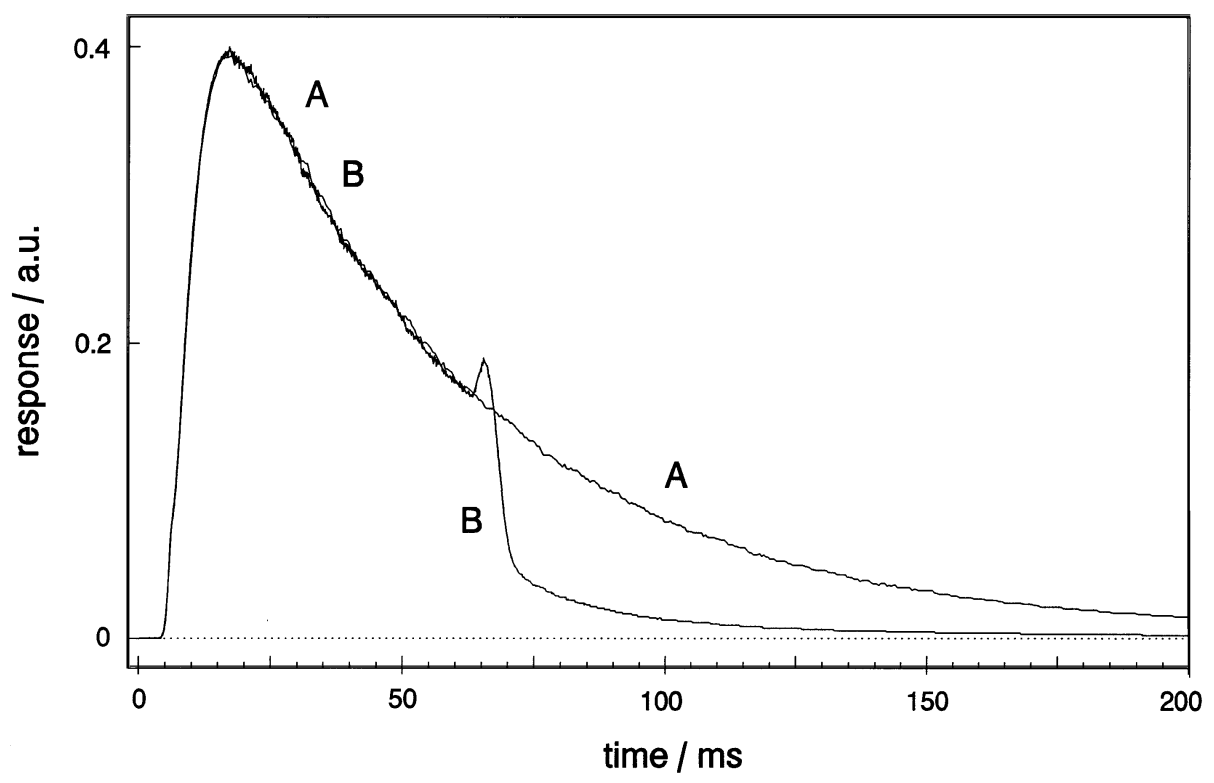

FIG. 4. Responses of oxygen as a function of time at a temperature of $1050 \mathrm{~K}$ for $0.13 \mathrm{~g}$ of $\mathrm{MgO}$ with a pulse intensity of $9 \times 10^{16} \mathrm{molecules}$ for oxygen. Line A, pulse experiment of oxygen. Line B, alternating pulse experiment of oxygen followed by methane at a time interval of $0.06 \mathrm{~s}$. Admitted methane to oxygen molar ratio of 0.5 .

Six different time intervals were applied between the oxygen and ethane pulse, varying from zero up to $5 \mathrm{~s}$ at a temperature of $973 \mathrm{~K}$. The corresponding conversion of ethane decreases from 69 to $57 \%$, the latter being equal to that obtained during the interaction of ethane with surface lattice oxygen alone. The yield of carbon monoxide and carbon dioxide decreases accordingly. The produced amount of ethene was already low in the case of simultaneous pulsing and vanishes completely at the smallest time interval which was applied, i.e., $20 \mathrm{~ms}$.

In the case of ethene and carbon monoxide alternating pulse experiments were carried out at 973 and $773 \mathrm{~K}$. The conversions decrease from 57 and $98 \%$ at a time interval of $0 \mathrm{~s}$ to 51 and $93 \%$ at a time interval of $4 \mathrm{~s}$. For ethene the yields of carbon monoxide and carbon dioxide decrease accordingly. The final conversion levels are identical to those obtained during the interaction of ethene and carbon monoxide with surface lattice oxygen alone.

$\mathrm{MgO}$. At a temperature of $1050 \mathrm{~K}$ six different time intervals were applied between the oxygen and the methane pulse, varying from simultaneous pulsing up to $0.09 \mathrm{~s}$. Since strongly adsorbed oxygen species are not present in the case of $\mathrm{MgO}$ a closed oxygen balance can be obtained during a single pulse of oxygen. A typical response of oxygen is presented in Fig. 4 together with a response resulting from pulsing oxygen alone. As soon as methane is introduced into the reactor, the response of oxygen abruptly decreases. This behavior is attributed to the conversion of weakly adsorbed oxygen species by methane, which are created by dioxygen as shown in the previous section.
The amount of weakly adsorbed oxygen being titrated by methane is calculated from the difference in the surface area of both responses for all the different time intervals applied, as proposed by Buyevskaya et al. (26). The second maximum in the oxygen response is attributed to a pressure wave due to the introduction of methane and argon, rather than to desorption of weakly molecularly adsorbed species, as proposed by Buyevskaya et al. (26).

In Fig. 5 the conversion of methane versus the amount of weakly adsorbed oxygen, expressed as a percentage of a theoretical monolayer, is presented. The conversion of methane amounts to $4 \%$ in the presence of surface lattice oxygen alone.

The yields of ethane, carbon monoxide, and carbon dioxide versus the amount of weakly adsorbed oxygen are presented in Fig. 6, together with the values obtained in the presence of surface lattice oxygen alone. The yield of ethane and carbon monoxide is almost constant, while that of carbon dioxide increases with increasing amount of weakly adsorbed oxygen.

\section{Reactivity of Surface Lattice Oxygen}

The reactivity of surface lattice oxygen was investigated by multipulse experiments of methane alone with a $0.4-\mathrm{s}$ time interval between the pulses. A time interval of $5 \mathrm{~min}$ between the oxygen treatment and the start of the experiment was applied, during which both strongly and weakly adsorbed oxygen species were removed from the surface.

$\mathrm{Sn} / \mathrm{Li} / \mathrm{MgO}$. The surface area of the individual responses of methane initially increases and finally remains 


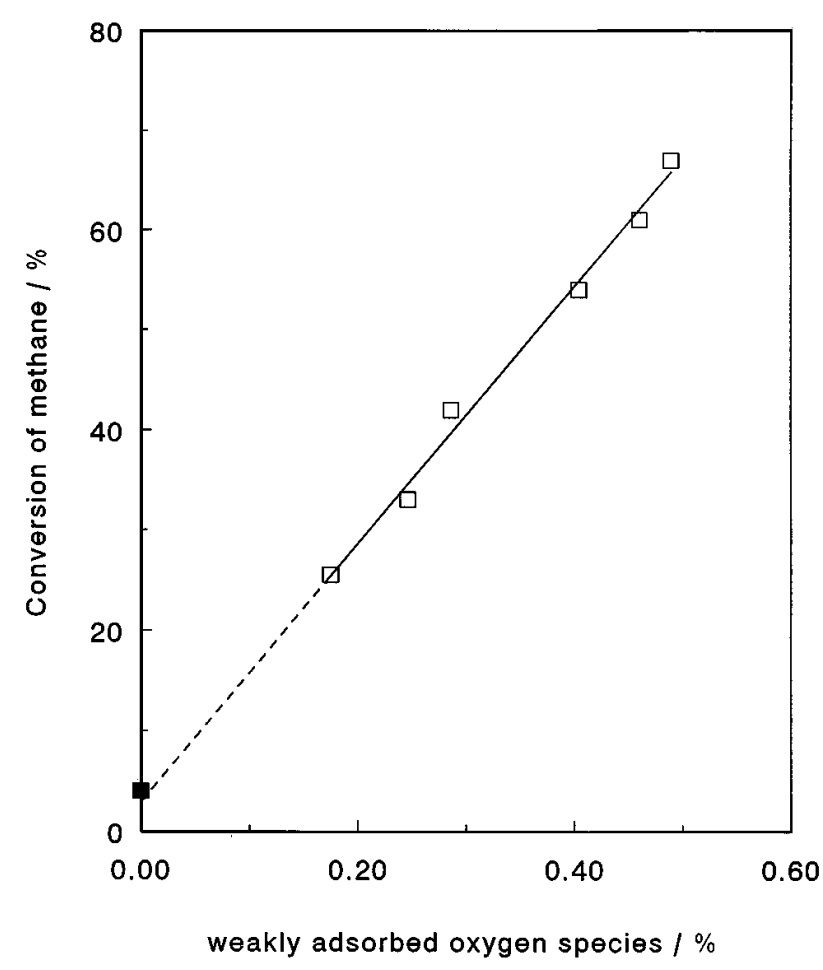

FIG. 5. Conversion of methane versus the amount of adsorbed oxygen, expressed as a percentage of a theoretical monolayer, for $0.13 \mathrm{~g}$ of $\mathrm{MgO}$ at a temperature of $1050 \mathrm{~K}$. Admitted methane to oxygen molar ratio of 0.5 and a pulse intensity of $5 \times 10^{16}$ molecules for methane. Filled square denotes the methane conversion obtained in the presence of surface lattice oxygen alone.

constant. Figure 7 presents the conversion of methane and yield of ethane as a function of the pulse number. At the first pulse of methane the conversion amounts of $43 \%$, while the yield of ethane amounts of $0.46 \%$ and that of carbon monoxide to $0.12 \%$. These values are identical to those obtained in the alternating pulse experiment applying a time interval of $10 \mathrm{~s}$ between the oxygen and methane pulse. The decrease of the methane conversion is much more pronounced compared to that of the yield of ethane.

The total amount of reactive surface lattice oxygen was determined from the amount of converted methane with the assumption that carbon dioxide and water are the only reaction products, i.e., corresponding to the consumption of four oxygen atoms per converted methane molecule. The assumption is valid, since the combined yield to ethane and carbon monoxide is less than $1 \%$.

The amount of reactive surface lattice oxygen is presented in Table 3, expressed as a percentage of a theoretical monolayer, and amounts to $44 \%$ at $1023 \mathrm{~K}$. The activation energy for methane conversion amounts to $86 \mathrm{~kJ} \mathrm{~mol}^{-1}$ as derived from the first pulse of the multipulse experiment.

$\mathrm{Li} / \mathrm{MgO}$. The surface area of the individual responses increases are finally remains constant. The amount of

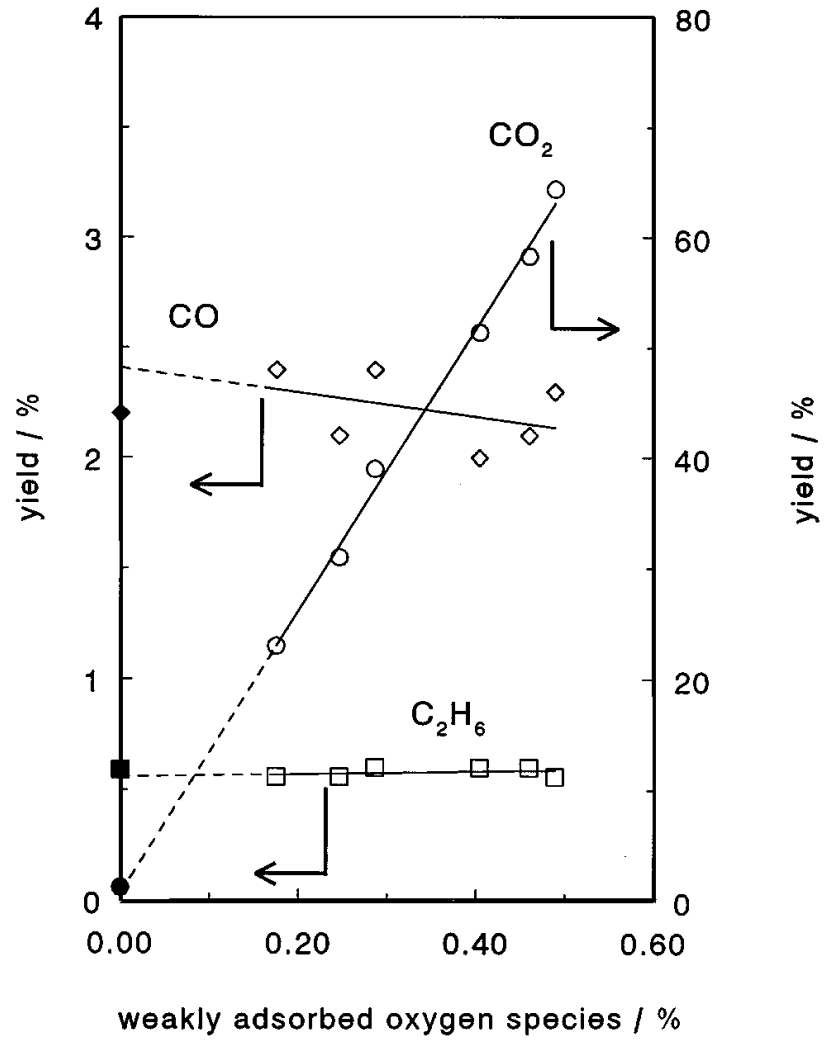

FIG. 6. Yield of ethane, carbon monoxide, and carbon dioxide versus the amount of adsorbed oxygen, expressed as a percentage of a theoretical monolayer, for $0.13 \mathrm{~g}$ of $\mathrm{MgO}$ at a temperature of $1050 \mathrm{~K}$. Admitted methane to oxygen molar ratio of 0.5 and a pulse intensity of $5 \times 10^{16}$ molecules for methane. Filled symbols denote the yields obtained in the presence of surface lattice oxygen alone.

reactive surface lattice oxygen is presented in Table 3. As in the case of $\mathrm{Sn} / \mathrm{Li} / \mathrm{MgO}$, the amount increases at increasing temperature and corresponds to $42 \%$ of a theoretical monolayer at $1048 \mathrm{~K}$. However, the percentage of reactive surface lattice oxygen is always low compared to that of $\mathrm{Sn} /$ $\mathrm{Li} / \mathrm{MgO}$ at the same temperature. The activation energy for methane conversion amounts to $85 \mathrm{~kJ} \mathrm{~mol}^{-1}$ as derived from the first pulse of the multipulse experiment.

$M g O$. The surface area of the individual methane responses is constant, except for the first pulse. The amount of reactive surface lattice oxygen is less than $0.1 \%$ of a theoretical monolayer at temperatures between 873 and $1073 \mathrm{~K}$. During the first pulse at $1048 \mathrm{~K}$ the conversion of methane amounts to $4 \%$, while the yield to ethane amounts to $0.59 \%$ and that to carbon monoxide to $2.2 \%$.

\section{DISCUSSION}

\section{Reaction Network}

Based on previous work (37) a reaction network for the oxidative coupling of methane over $\mathrm{Sn} / \mathrm{Li} / \mathrm{MgO}$ in the 


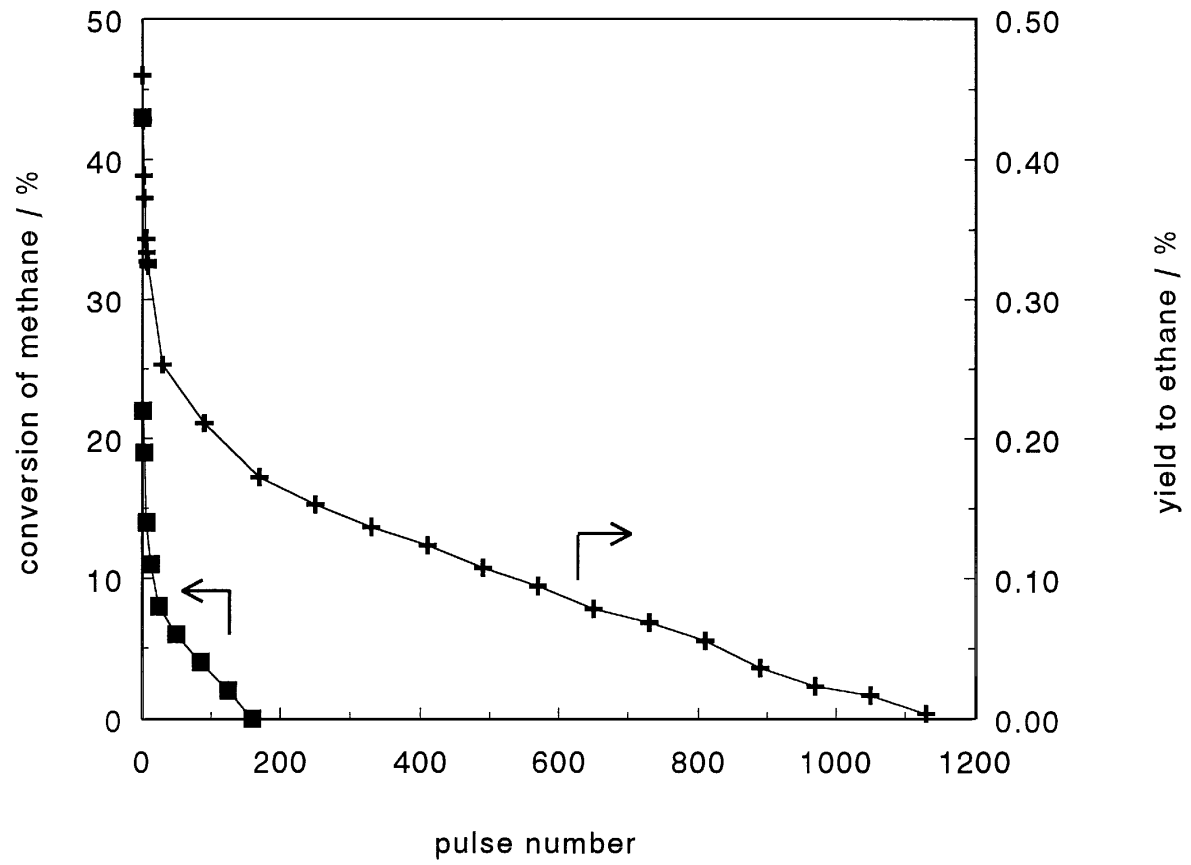

FIG. 7. Conversion of methane and yield of ethane as a function of the pulse number. Multipulse experiment of methane over $0.42 \mathrm{~g}$ of Sn/Li/ $\mathrm{MgO}$ at a temperature of $973 \mathrm{~K}$ and a pulse intensity of $7 \times 10^{16}$ molecules.

presence of both methane and oxygen at $973 \mathrm{~K}$ was proposed, which is shown in Fig. 8.

Methyl radicals are produced at the catalyst surface and combine in the gas phase to form ethane $(4,38)$. Ethene is produced from ethane via a gas phase reaction in which dioxygen is involved. It is assumed that this reaction occurs via surface-generated ethyl radicals, as shown for $\mathrm{Li}$ $/ \mathrm{MgO}$ (39). Both ethane and ethene are oxidized to carbon monoxide at the surface. Carbon monoxide is oxidized to carbon dioxide by interaction with the surface $(21,40)$. In parallel to the formation of ethane, methane is directly converted to carbon dioxide.

The present study allows us to specify the role of both adsorbed and surface lattice oxygen in the oxidative coupling of methane.

\section{TABLE 3}

Amount of Reactive Surface Lattice Oxygen, Expressed as a Percentage of a Theoretical Monolayer, for $0.40 \mathrm{~g}$ of $\mathrm{Li} /$ $\mathrm{MgO}$ and $0.42 \mathrm{~g}$ of $\mathrm{Sn} / \mathrm{Li} / \mathrm{MgO}$ at Various Temperatures, as Obtained from Multipulse Experiments of Methane with a Pulse Intensity of $7 \times 10^{16}$ Molecules

\begin{tabular}{rcc}
\hline $\mathrm{T}(\mathrm{K})$ & $\mathrm{Li} / \mathrm{MgO}(\%)$ & $\mathrm{Sn} / \mathrm{Li} / \mathrm{MgO}(\%)$ \\
\hline 923 & 0.9 & 6.7 \\
948 & 1.6 & 11.3 \\
973 & 2.8 & 16.7 \\
998 & 7.7 & 29.2 \\
1023 & 27.2 & 43.9 \\
1048 & 41.6 & - \\
\hline
\end{tabular}

\section{Interaction of Oxygen with the Surface}

The results of the multipulse experiments (see Fig. 1) indicate that in the case of $\mathrm{Li} / \mathrm{MgO}$ and $\mathrm{Sn} / \mathrm{Li} / \mathrm{MgO}$ both strongly and weakly adsorbed oxygen species are present on the surface. However, for $\mathrm{MgO}$ only weakly adsorbed oxygen exists. This result is in line with those of Nakamura et al. (41), who studied the formation of adsorbed oxygen species by the decomposition of $\mathrm{N}_{2} \mathrm{O}$ on $\mathrm{MgO}$ and $\mathrm{Li} / \mathrm{MgO}$. The temperature programmed desorption of the oxygen species revealed that two types of adsorbed species were present on $\mathrm{Li} / \mathrm{MgO}$, referred to as $\alpha$ - and $\beta$-oxygen species. A weak $\alpha$-oxygen peak occurred on $\mathrm{MgO}$ and no $\beta$-oxygen peak was observed.

For the present study, the formation of weakly adsorbed oxygen species on the promoted catalysts is attributed to the interaction of dioxygen with the $\mathrm{MgO}$ phase. The presence of the strongly adsorbed oxygen species is related to a lithium-containing phase. Peng et al. (42) reported two forms of lithium, i.e., $\mathrm{Li}^{+} \mathrm{O}^{-}$centers and $\mathrm{Li}_{2} \mathrm{CO}_{3}$, on the surface of $\mathrm{Li} / \mathrm{MgO}$ under reaction conditions. For the $\mathrm{Li} /$ $\mathrm{MgO}$ and $\mathrm{Sn} / \mathrm{Li} / \mathrm{MgO}$ catalysts two crystalline phases were detected by XRD measurements: $\mathrm{MgO}$ and $\mathrm{Li}_{2} \mathrm{CO}_{3}$ (31).

During the pretreatment of the promoted catalysts large amounts of carbon dioxide were detected quantitatively. This is assigned to the decomposition of the $\mathrm{Li}_{2} \mathrm{CO}_{3}$ phase into a $\mathrm{Li}_{2} \mathrm{O}$ phase, which leads to the conclusion that $\mathrm{Li}_{2} \mathrm{O}$ is present as well at the experimental conditions of the present study. However, it is not clear whether both phases are si-

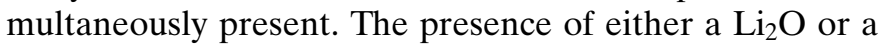




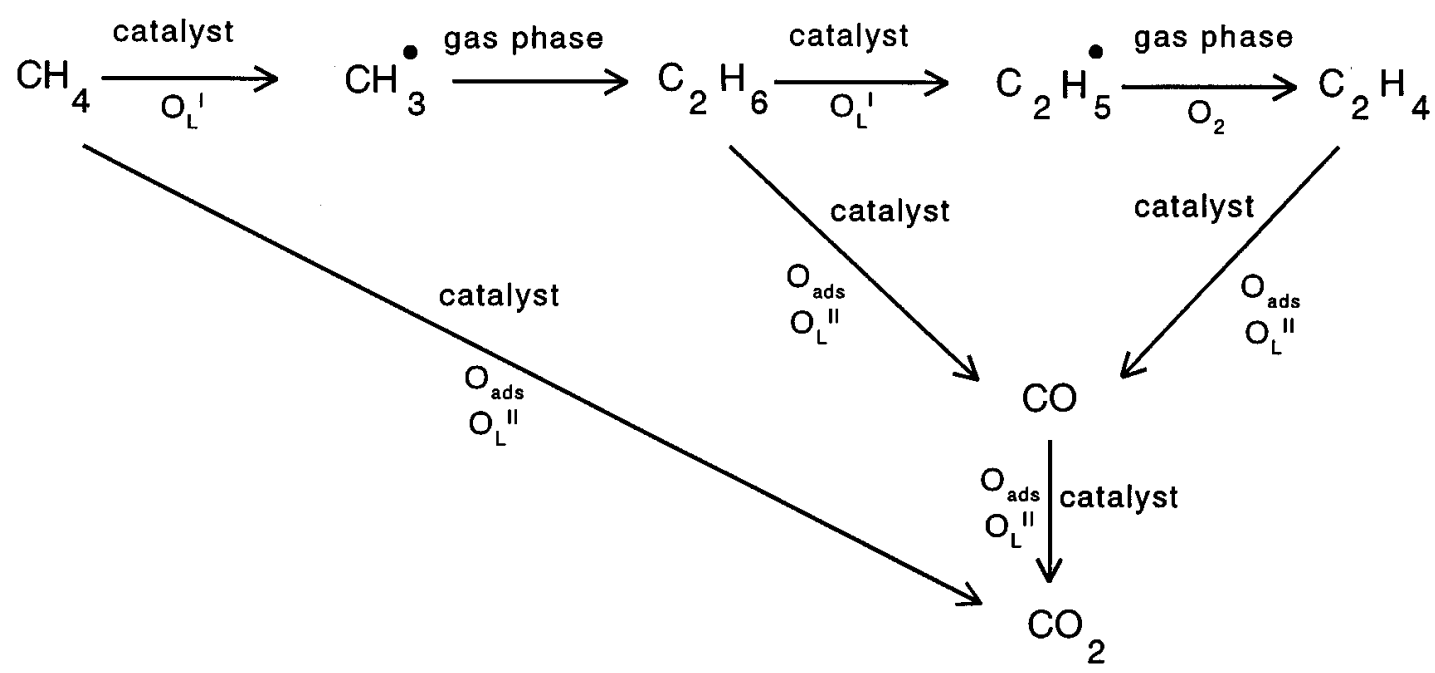

FIG. 8. Reaction network and role of different oxygen species in the oxidative coupling of methane in the presence of oxygen over Sn/Li/MgO at $973 \mathrm{~K}, \mathrm{O}_{\mathrm{ads}}$, weakly adsorbed oxygen species; $\mathrm{O}_{\mathrm{L}}^{\mathrm{I}}$, first type of reactive surface lattice oxygen; and $\mathrm{O}_{\mathrm{L}}^{\mathrm{II}}$, second type of reactive surface lattice oxygen.

$\mathrm{Li}_{2} \mathrm{CO}_{3}$ phase is considered to be responsible for the formation of strongly adsorbed oxygen in case of the promoted catalysts.

The amount of strongly adsorbed oxygen increases with increasing temperature, as shown in Table 2 and is essentially identical for $\mathrm{Li} / \mathrm{MgO}$ and $\mathrm{Sn} / \mathrm{Li} / \mathrm{MgO}$. Peng et al. (42) reported that in case of $\mathrm{Li} / \mathrm{MgO}$ at lithium loadings of 1 to $10 \mathrm{wt} \%$ the concentration of $\mathrm{Li}^{+} \mathrm{O}^{-}$and $\mathrm{Li}_{2} \mathrm{CO}_{3}$ at the surface did not change. Assuming that this is also the case for $\mathrm{Sn} / \mathrm{Li} / \mathrm{MgO}$ this observation explains the identical amounts of strongly adsorbed oxygen reported for both promoted catalysts, though the percentage of lithium is different for $\mathrm{Li} / \mathrm{MgO}$ and $\mathrm{Sn} / \mathrm{Li} / \mathrm{MgO}$ (see Table 1 ).

The interaction of oxygen with the surface via weakly adsorbed oxygen species was investigated by pulse experiments with labeled oxygen. Nibbelke et al. (22) observed that both surface and lattice oxygen participate in the oxygen exchange reaction for $\mathrm{Li} / \mathrm{MgO}$ and $\mathrm{Sn} / \mathrm{Li} / \mathrm{MgO}$. It can be assumed that for all catalysts in the present study solely the interaction of labeled dioxygen with surface lattice oxygen was studied. Indeed, the average residence time of oxygen in the catalyst bed amounts to $0.1 \mathrm{~s}$, whereas the characteristic time for diffusion of oxygen through one layer of the bulk lattice amounts to $190 \mathrm{~s}$ in the case of $\mathrm{MgO}$ and to $1 \mathrm{~s}$ in the case of $\mathrm{Sn} / \mathrm{Li} / \mathrm{MgO}$, based on values of the diffusion coefficients estimated by Nibbelke et al. (22) and a distance between two layers of $1.98 \times 10^{-10} \mathrm{~m}$. Hence, the characteristic time for diffusion of oxygen into one monolayer of the bulk is one to three orders of magnitude larger than the average residence time in the reactor.

The results indicate that the adsorption of oxygen is reversible and dissociative on both $\mathrm{MgO}$ and $\mathrm{Sn} / \mathrm{Li} / \mathrm{MgO}$, since formation of ${ }^{16} \mathrm{O}^{18} \mathrm{O}$ was observed. The normalized response of ${ }^{16} \mathrm{O}^{18} \mathrm{O}$ is observed prior to that of ${ }^{16} \mathrm{O}_{2}$ (see
Fig. 3), which points to the primary formation of ${ }^{16} \mathrm{O}^{18} \mathrm{O}$ followed by ${ }^{16} \mathrm{O}_{2}$. The result is in line with a mechanism proposed by Winter $(43,44)$, who studied the kinetics of oxygen exchange between labelled oxygen and several metal oxides, including $\mathrm{MgO}$,

$$
\begin{array}{r}
{ }^{18} \mathrm{O}_{2}+{ }^{16} \mathrm{O}_{\text {lattice }} \leftrightarrows{ }^{16} \mathrm{O}^{18} \mathrm{O}+{ }^{18} \mathrm{O}_{\text {lattice }} \\
{ }^{16} \mathrm{O}^{18} \mathrm{O}+{ }^{16} \mathrm{O}_{\text {lattice }} \leftrightarrows{ }^{16} \mathrm{O}_{2}+{ }^{18} \mathrm{O}_{\text {lattice }},
\end{array}
$$

i.e., involving the participation of a single atom of lattice oxygen in the oxygen exchange reaction.

The conversion of labeled dioxygen into exchange products increases at increasing temperature with an increasing yield to the consecutive exchange product ${ }^{16} \mathrm{O}_{2}$. For $\mathrm{Sn} / \mathrm{Li} /$ $\mathrm{MgO}$ a maximum in the yield to ${ }^{16} \mathrm{O}^{18} \mathrm{O}$ was observed in the investigated temperature range. The activation energy for oxygen exchange on $\mathrm{MgO}$ amounts to $120 \mathrm{~kJ} \mathrm{~mol}^{-1}$, which is in the same order of magnitude as the value of $159 \mathrm{~kJ}$ $\mathrm{mol}^{-1}$ reported by Winter (43) for $\mathrm{MgO}$.

Winter postulated that the exchange reaction was confined to the surface layer, as is the case in the present study. However, the activation energy of $120 \mathrm{~kJ} \mathrm{~mol}^{-1}$ is much lower than the value of $261 \mathrm{~kJ} \mathrm{~mol}^{-1}$ reported by Buyevskaya et al. (26) for the oxygen exchange on $\mathrm{MgO}$. The authors compare their value to the activation energy of $266 \mathrm{~kJ} \mathrm{~mol}^{-1}$ for oxygen diffusion in the bulk of $\mathrm{MgO}$ (20) and argue that oxygen diffusion might be the rate limiting step under the applied conditions. In the case of $\mathrm{Sn} / \mathrm{Li} / \mathrm{MgO}$ the activation energy for oxygen exchange is much lower compared to $\mathrm{MgO}$, amounting to $35 \mathrm{~kJ} \mathrm{~mol}^{-1}$. The large decrease in the activation energy leads to a large increase in the concentration of oxygen on the catalysts available for exchange with gas phase oxygen due to the promotion with lithium and tin (22). For MgO the concentration of oxygen 
on the catalyst only amounts to $10 \%$ of a theoretical monolayer, while for the lithium-promoted catalysts, especially for $\mathrm{Sn} / \mathrm{Li} / \mathrm{MgO}$, the value of a theoretical monolayer is exceeded. This phenomenon is attributed to subsurface oxygen immediately available for exchange by Peil et al. (20). A different explanation is that in the case of the lithiumpromoted catalysts the exchange of oxygen occurs via the lithium oxide phase.

\section{Reactivity of Adsorbed Oxygen Species}

The weakly adsorbed oxygen species are very reactive toward methane compared to surface lattice oxygen, as shown in Fig. 5. A linear dependence of the methane conversion on the amount of weakly adsorbed oxygen species is observed for $\mathrm{MgO}$. The extrapolated conversion of methane in the absence of adsorbed oxygen species agrees well with the experimentally observed value of $4 \%$ in the presence of surface lattice oxygen alone.

In the case of $\mathrm{Sn} / \mathrm{Li} / \mathrm{MgO}$ the conversion of methane decreases due to the disappearance of adsorbed species and reaches a constant value after a time interval of 4 between the oxygen and the methane pulse. The final conversion level is identical to the value obtained during the interaction of methane with surface lattice oxygen alone.

The strongly adsorbed oxygen species are still present after a time interval of $4 \mathrm{~s}$ up to $3 \mathrm{~min}$, which leads to the conclusion that these species are not active in the methane conversion at all.

For both catalysts the yields of ethane and carbon monoxide do not depend on the concentration of weakly adsorbed oxygen species and are identical to the yields obtained during the interaction of methane with surface lattice oxygen alone, as shown in Fig. 6 for MgO. This leads to the conclusion that in the presence of weakly adsorbed oxygen, denoted $\mathrm{O}_{\text {ads }}$ in Fig. 8, methane is directly converted to carbon dioxide. This reaction occurs in parallel to the activation of methane via surface lattice oxygen. A direct reaction path from methane to carbon dioxide was also concluded when pulsing methane and oxygen simultaneously over $\mathrm{MgO}$ (37).

In the case of ethane, ethene, and carbon monoxide both surface lattice oxygen and weakly adsorbed oxygen species are involved in the nonselective reaction paths. At increasing time interval between the oxygen and reductant pulse the conversion and yields to the products decrease and finally a constant level identical to the values obtained in the presence of the surface lattice oxygen alone is reached. Strongly adsorbed oxygen species are not reactive toward these reductants at all.

The reactivity of $\mathrm{Sn} / \mathrm{Li} / \mathrm{MgO}$ toward ethane is higher than that of ethene, which is in line with the difference in the dissociation energy of the $\mathrm{C}-\mathrm{H}$ bond in ethane of 418 $\mathrm{kJ} \mathrm{mol}^{-1}$ and ethene of $443 \mathrm{~kJ} \mathrm{~mol}^{-1}$ (45) and with the observation that ethene shows no significant interaction with the catalyst (22). At first sight, ethene is expected to exhibit a stronger interaction with the catalyst than methane because of the double bond in ethene. The high basicity of Sn $/ \mathrm{Li} / \mathrm{MgO}$ probably prevents the interaction of ethene with the catalyst.

\section{Reactivity of Surface Lattice Oxygen}

The amount of surface lattice oxygen which is reactive toward methane is less than $0.1 \%$ of a theoretical monolayer in the case of $\mathrm{MgO}$ up to temperatures of $1073 \mathrm{~K}$. For Li/ $\mathrm{MgO}$ and $\mathrm{Sn} / \mathrm{Li} / \mathrm{MgO}$ the percentage of reactive surface lattice oxygen is one to two orders of magnitude higher and the amount increases at increasing temperature. The $\mathrm{Sn} / \mathrm{Li} /$ $\mathrm{MgO}$ catalyst possesses the highest amount at a comparable temperature (see Table 3).

In the investigated temperature range the amount of reactive surface lattice oxygen is always less than one theoretical monolayer of atomic oxygen. Sinev et al. (46) reported the removal of an amount of oxygen equivalent to $40 \%$ of a theoretical monolayer by exposure of $\mathrm{Li} / \mathrm{MgO}$ to hydrogen at $823 \mathrm{~K}$, which is in the same order of magnitude as reported in the present study.

The addition of a reducible oxide, such as $\mathrm{SnO}_{2}$, to $\mathrm{Li} /$ $\mathrm{MgO}$ further increases the activity of the catalyst (35, 4749). The oxidation state of $\mathrm{Sn}$ in the $\mathrm{Sn} / \mathrm{Li} / \mathrm{MgO}$ catalyst was investigated by means of Mössbauer spectroscopy. The results showed that the bulk Sn phase consisted only of $\mathrm{SnO}_{2}$ when the catalyst was pretreated with pure oxygen or a methane and oxygen mixture at $1023 \mathrm{~K}$. In the latter case a methane to oxygen molar ratio of 10 was applied and complete conversion of oxygen was achieved. However, 30 at. \% was in the form of metallic Sn after pretreatment with pure methane at $1023 \mathrm{~K}$. No SnO was detected quantitatively after any of the above pretreatments.

The decrease of the methane conversion and the yield of ethane with increasing pulse number is different on both $\mathrm{Sn} /$ $\mathrm{Li} / \mathrm{MgO}$ and $\mathrm{Li} / \mathrm{MgO}$ (see Fig. 7). This points to two different types of surface lattice oxygen, one type being involved in the selective conversion of methane to ethane, denoted $\mathrm{O}_{\mathrm{L}}^{\mathrm{I}}$ in Fig. 8. A second type, $\mathrm{O}_{\mathrm{L}}^{\mathrm{II}}$, is reactive in the nonselective conversion of methane to carbon dioxide, as concluded from the fast decrease in the methane conversion.

\section{Comparison between $\mathrm{MgO}, \mathrm{Li} / \mathrm{MgO}$, and $\mathrm{Sn} / \mathrm{Li} / \mathrm{MgO}$}

The identical activation energy for the interaction of oxygen via weakly and strongly adsorbed oxygen with $\mathrm{Sn} / \mathrm{Li}$ / $\mathrm{MgO}$ points to a common rate determining step for the formation of both types of species. A possible mechanism is the formation of weakly adsorbed species via oxygen vacancies in the $\mathrm{MgO}$ phase, after which species adsorbed in the neighborhood of a $\mathrm{Li}_{2} \mathrm{O}$ or a $\mathrm{Li}_{2} \mathrm{CO}_{3}$ phase are transferred to this phase via spillover. The amount of the oxygen vacancies in the $\mathrm{MgO}$ lattice increases due to the addition of lithium to $\mathrm{MgO}$ (50). 
The activation energy for the formation of both weakly and strongly adsorbed oxygen species decreases in the order of $\mathrm{MgO}, \mathrm{Li} / \mathrm{MgO}$, and $\mathrm{Sn} / \mathrm{Li} / \mathrm{MgO}$. Dioxygen must be converted to the form of $\mathrm{O}^{-}$or $\mathrm{O}^{2-}$ at the surface before it reacts and apparently the addition of lithium and moreover tin facilities this process.

The activation energy for methane conversion over surface lattice oxygen amounts for $\mathrm{Li} / \mathrm{MgO}$ and $\mathrm{Sn} / \mathrm{Li} / \mathrm{MgO}$ to 85 and $86 \mathrm{~kJ} \mathrm{~mol}^{-1}$, respectively, which indicates that the reaction proceeds on both catalysts via a common rate determining step. These values are in reasonable agreement with literature results. A value of $54 \mathrm{~kJ} \mathrm{~mol}^{-1}$ was reported for the interaction of methane with $\mathrm{Li} / \mathrm{MgO}$ in the absence of dioxygen (51), while values of $87 \mathrm{~kJ} \mathrm{~mol}^{-1}$ for $\mathrm{Li} / \mathrm{MgO}$ (52) and $123 \mathrm{~kJ} \mathrm{~mol}^{-1}$ for $\mathrm{Sn} / \mathrm{Li} / \mathrm{MgO}$ (31) were reported for the methane interaction step with the surface.

An increase in the activity of $\mathrm{Li} / \mathrm{MgO}$ by the addition of $\mathrm{SnO}_{2}$ was reported by Korf et al. (35), as concluded from the lower reaction temperature necessary in the case of $\mathrm{Sn} /$ $\mathrm{Li} / \mathrm{MgO}$ for identical oxygen conversion and yields to $\mathrm{C}_{2}$ products. The value of the activation energy for the catalytic activation step of methane is identical for both catalysts, as mentioned in the previous paragraph. The value of the preexponential factor for this reaction step is also identical for both $\mathrm{Li} / \mathrm{MgO}$ and $\mathrm{Sn} / \mathrm{Li} / \mathrm{MgO}$, as reported by Couwenberg (31). Therefore, the increase in the activity of $\mathrm{Sn} / \mathrm{Li} / \mathrm{MgO}$ compared to $\mathrm{Li} / \mathrm{MgO}$ is attributed to the observed increase in the amount of reactive surface lattice oxygen. The latter results from an increase in the lattice oxygen mobility, as indicated by an increasing oxygen diffusion coefficient in the bulk of the lattice (Nibbelke et al. (22)). Indeed, at 1000 $\mathrm{K}$ the ratio of the amount of reactive surface lattice oxygen of $\mathrm{Sn} / \mathrm{Li} / \mathrm{MgO}$ compared to $\mathrm{Li} / \mathrm{MgO}$ amounts to 1.6. The ratio compares quite well with the rate of the heterogeneous methane activation for both catalysts, expressed per unit BET surface area, of 2.4 at $1023 \mathrm{~K}, 110 \mathrm{kPa}$, and an initial methane to oxygen molar ratio of 4 , which follows from values for the reaction rate coefficients estimated by Couwenberg (31).

\section{Reaction Mechanism}

In spite of the low yields of $\mathrm{C}_{2}$ products, the results of the present study are relevant for the heterogeneous reaction steps in the oxidative coupling of methane, where a typical yield of $20 \%$ is obtained with $\mathrm{Sn} / \mathrm{Li} / \mathrm{MgO}$ (31).

The interaction of methane and oxygen with the catalyst has been investigated at an average pressure of $1000 \mathrm{~Pa}$, which is low compared to industrially relevant pressures which are in the range of 100 to $1000 \mathrm{kPa}$. The coupling of two methyl radicals to ethane has to occur in the gas phase but is at $1000 \mathrm{~Pa}$ in the low pressure regime according to the unimolecular rate theory of Rice-RamspergerKassel- Marcus (53) and pressure fall-off data from the literature (54). Ethene is not detected at $1000 \mathrm{~Pa}$ since the formation also has to occur in the gas phase by involvement of dioxygen. The direct decomposition of ethyl radicals toward ethene can be ruled out at pressures of 1000 $\mathrm{Pa}$ (54). Hence, as a result of the low pressures the yield of $\mathrm{C}_{2}$ products is less than $1 \%$ in the present study and the experimental data obtained with methane pulses will provide information on the generation of methyl radicals rather than on the global coupling reaction.

The role of different oxygen forms in the oxidative coupling of methane over $\mathrm{Sn} / \mathrm{Li} / \mathrm{MgO}$ in the presence of both methane and oxygen can be specified and is shown in Fig. 8, together with the proposed network.

The formation of methyl radicals from methane proceeds via one form of surface lattice oxygen, denoted $\mathrm{O}_{\mathrm{L}}^{\mathrm{I}}$ in Fig. 8 . It seems likely that these sites are also involved in the formation of ethyl radicals from ethane.

Both weakly adsorbed oxygen species, $\mathrm{O}_{\text {ads }}$, and a second form of surface lattice oxygen, $\mathrm{O}_{\mathrm{L}}^{\mathrm{II}}$, are involved in the nonselective reaction path of methane to carbon dioxide.

The oxidation of ethane and ethene to carbon dioxide and the consecutive oxidation of carbon monoxide also proceed via weakly adsorbed oxygen species, $\mathrm{O}_{\text {ads }}$. Surface lattice oxygen is involved as well and it seems likely that only the nonselective form, $\mathrm{O}_{\mathrm{L}}^{\mathrm{II}}$, contributes to these reactions. Strongly adsorbed oxygen species are not involved in the reaction mechanism of the oxidative coupling of methane.

Peil et al. (20) propose two parallel carbon pathways for the conversion of methane over $\mathrm{Li} / \mathrm{MgO}$, one for the formation of $\mathrm{C}_{2} \mathrm{H}_{6}$ and the second for $\mathrm{CO}_{\mathrm{x}}$ formation. The sites for the carbon reaction pathway involved in the formation of $\mathrm{C}_{2} \mathrm{H}_{6}$ have a lower activity than sites involved in the formation of $\mathrm{CO}$ and $\mathrm{CO}_{2}$. Also, $\mathrm{CO}$ and $\mathrm{CO}_{2}$ may be formed sequentially on the surface, with lattice oxygen participating in the reaction. Parallel formation of $\mathrm{C}_{2} \mathrm{H}_{6}$ and $\mathrm{CO}_{x}$ over $\mathrm{Li} / \mathrm{MgO}$ has also been reported by Mirodatos et al. (30) and Nelson et al. (29). A possible mechanism is that methyl radicals either desorb and couple in the gas phase to form $\mathrm{C}_{2} \mathrm{H}_{6}$ or react with surface oxygen to produce $\mathrm{CO}_{x}$.

The direct formation of $\mathrm{CO}_{2}$ from methane over $\mathrm{Sn} / \mathrm{Li} /$ $\mathrm{MgO}$ is in line with the work of Nibbelke et al. (22) and Couwenberg (31). Under reaction conditions a strong interaction of both the oxygen and carbon atoms leading to carbon dioxide was observed due to the surface catalyzed formation of $\mathrm{CO}_{2}$ as well as the interaction of $\mathrm{CO}_{2}$ with the catalyst. The latter is believed to be the result of transformation of lithium oxide, $\mathrm{Li}_{2} \mathrm{O}$, into lithium carbonate, $\mathrm{Li}_{2} \mathrm{CO}_{3}$, by $\mathrm{CO}_{2}$. A methoxy species was postulated as the intermediate in the reaction path to $\mathrm{CO}_{2}$, based on modeling results. Bytyn and Baerns (55) also proposed formation of a methoxy species in the nonselective pathways of the oxidative coupling of methane over supported $\mathrm{PbO}$ catalysts.

The network proposed in Fig. 8 is consistent with the following mechanism for the production of methyl radicals, 
in line with that originally proposed by Lunsford and coworkers (4):

$$
\begin{aligned}
\mathrm{O}_{2}+2 * & \leftrightarrows 2 \mathrm{O} * \\
\mathrm{CH}_{4}+\mathrm{O} * & \rightarrow \mathrm{OH} *+\mathrm{CH}_{3} . \\
\mathrm{OH} *+\mathrm{OH} * & \rightarrow \mathrm{H}_{2} \mathrm{O}+\mathrm{O} *+*
\end{aligned}
$$

The reversible chemisorption of dioxygen followed by transformation leading to the four different forms of oxygen species is summarized by reaction [9]. Only one of these forms, denoted $\mathrm{O}_{\mathrm{L}}^{\mathrm{I}}$ in Fig. 8, is involved in the $\mathrm{H}$ abstraction from methane according to an Eley-Rideal mechanism, as described by reaction [10]. It was shown by Chen et al. (56) that the rate of regeneration of the active sites, reaction [11], is kinetically significant on $\mathrm{Sn} / \mathrm{Li} / \mathrm{MgO}$. The rate of transformation leading to $\mathrm{O}_{\mathrm{L}}^{\mathrm{I}}$ and possibly that of regeneration of active sites may be increased by an increasing lattice oxygen mobility.

\section{CONCLUSIONS}

Two types of oxygen species are present on the surface of $\mathrm{Sn} / \mathrm{Li} / \mathrm{MgO}$. The first type is strongly adsorbed oxygen interacting with $\mathrm{Li}_{2} \mathrm{O}$ or $\mathrm{Li}_{2} \mathrm{CO}_{3}$ phase. This type of oxygen does not seem to be active in methane coupling. The second type of oxygen concerns weakly adsorbed oxygen species, which are involved in the direct conversion of methane to carbon dioxide.

The percentage of surface lattice oxygen active in the methane conversion is less than $0.1 \%$ for $\mathrm{MgO}$ but increases for $\mathrm{Li} / \mathrm{MgO}$ and even more $\mathrm{Sn} / \mathrm{Li} / \mathrm{MgO}$. On $\mathrm{Sn} / \mathrm{Li} / \mathrm{MgO}$ two types of surface lattice oxygen are present. The first type activates methane for the methyl radical formation, while the second is involved in the direct conversion of methane to carbon dioxide.

Both weakly adsorbed oxygen species and the second type of surface lattice oxygen are involved in the nonselective reaction paths of ethane and ethene as well as the consecutive oxidation of carbon monoxide.

The observations are consistent with the Lunsford mechanism for the generation of methyl radicals over $\mathrm{MgO}$ based catalysts. The increasing activity toward methane due to the addition of lithium and moreover tin to $\mathrm{MgO}$ can be explained by an increase in the amount of reactive surface lattice oxygen.

\section{ACKNOWLEDGMENT}

The financial support provided by the Commission of the European Union in the framework of the JOULE programme, subprogramme Energy from Fossil Sources, Hydrocarbons (JOUF-0044-C), is gratefully acknowledged. The Mössbauer spectroscopy measurements on $\mathrm{Sn} / \mathrm{Li} / \mathrm{MgO}$ were carried out by Dr. E. Boellaard from the Interfacultair Reactor Instituut of Delft University of Technology.

\section{REFERENCES}

1. Keller, G. E., and Bhasin, M. M., J. Catal. 73, 9 (1982).

2. Hinsen, W., and Baerns, M., Chem. Ztg. 107, 223 (1983).

3. Ito, T., and Lunsford, J. H., Nature 314, 712 (1985).

4. Ito, T., Wang, J.-X., Lin, C.-H., and Lunsford, J. H., J. Am. Chem. Soc. 107, 5062 (1985).

5. Driscoll, D. J., and Lunsford, J. H., J. Phys. Chem. 89, 4415 (1985).

6. Campbell, K. D., Morales, E., and Lunsford, J. H., J. Am. Chem. Soc. 109, 7900 (1987).

7. Campbell, K. D., and Lunsford, J. H., J. Phys. Chem. 92, 5792 (1988).

8. Driscoll, D. J., Martir, W., Wang, J.-X., and Lunsford, J. H., J. Am. Chem. Soc. 107, 58 (1985).

9. Lin, C. H., Ito, T., Wang, J.-X., and Lunsford, J. H., J. Am. Chem. Soc. 109, 4808 (1987).

10. Wang, J.-X., and Lunsford, J. H., J. Phys. Chem. 90, 5883 (1986).

11. Lunsford, J. H., Catal. Today 6, 3, 235 (1990).

12. Lin, C.-H., Campbell, K. D., Wang, J.-X., Lunsford, J. H., J. Phys. Chem. 90, 534 (1986).

13. Driscoll, D. J., Campbell, K. D., and Lunsford, J. H., Adv. Catal. 35, 139 (1987).

14. Che, M., and Tench, A. J., Adv. Catal. 31, 77 (1982).

15. Sokolovskii, V. D., Aliev, S. M., Buyevskaya, O. V., and Davydov, A. A., Catal. Today 4, 293 (1989).

16. Otsuka, K., Said, A. A., Jinno, K., and Komatsu, T., Chem. Lett. 77, (1987).

17. Kharas, K. C. C., and Lunsford, J. H., J. Am. Chem. Soc. 111, 2336 (1989).

18. Otsuka, K., Murakami, Y., Wada, Y., Said, A. A., and Morikawa, A., J. Catal. 121, 122 (1990).

19. Sinev, M. Y., Korchak, V. N., and Krylov, O. V., Kinet. Catal. 27, 1110 (1986).

20. Peil, K. P., Goodwin, J. G., and Marcelin, G., J. Catal. 131, 143 (1991).

21. Peil, K. P., Goodwin, J. G., and Marcelin, G., J. Phys. Chem. 93, 5977 (1989).

22. Nibbelke, R. H., Scheerová, J., de Croon, M. H. J. M., and Marin, G. B., J. Catal. 156, 106 (1995).

23. Cant, N. W., Lukey, C. A., and Nelson, P. F., J. Catal. 124, 336 (1990).

24. Kalenik, Z., and Wolf, E. E., Catal. Lett. 11, 309 (1991).

25. Kalenik, Z., and Wolf, E. E., Catal. Today 13, 255 (1992).

26. Buyevskaya, O. V., Rothaemel, M., Zanthoff, H. W., and Baerns, M., J. Catal. 150, 71 (1994).

27. Buyevskaya, O. V., Rothaemel, M., Zanthoff, H. W., and Baerns, M., J. Catal. 146, 346 (1996).

28. Ekstrom, A., and Lapszewicz, J. A., J. Phys. Chem. 93, 13, 5230 (1989).

29. Nelson, P. F., Lukey, C. A., and Cant, N. W., J. Catal. 120, 216 (1989).

30. Mirodatos, C., Holmen, A., Mariscal, R., and Martin, G. A., Catal. Today 6, 601 (1990).

31. Couwenberg, P. M., Ph.D. thesis, Eindhoven University of Technology, 1995.

32. Asami, K., Shikada, T., Fujimoto, K., and Tominaga, H., Ind. Eng. Chem. Res. 26, 11, 2348 (1987).

33. Sun, Y.-K., Lewandowski, J. T., Myers, G. R., Jacobson, A. J., and Hall, R. B., in "The Activation of Dioxygen and Homogeneous Catalytic Oxidation” (D. H. R. Barton, A. E. Martell, and D. Sawyer, Eds.), p. 97. Plenum, New York, 1993.

34. Efstathiou, A. M., Lacombe, S., Mirodatos, C., and Verykios, X. E., J. Catal. 148, 639 (1994).

35. Korf, S. J., Roos, J. A., Veltman, L. J., van Ommen, J. G., and Ross, J. R. H., Appl. Catal. 56, 119 (1989).

36. Gleaves, J. T., Ebner, J. R., and Kuechler, T. C., Catal. Rev.-Sci. Eng. 30, 1, 49 (1988). 
37. Mallens, E. P. J., Hoebink, J. H. B. J., and Marin, G. B., Stud. Surf. Sci. Catal. 81, 205 (1994).

38. Nelson, P. F., Lukey, C. A., and Cant, N. W., J. Phys. Chem. 92, 6176 (1988).

39. Morales, E., and Lunsford, J. H., J. Catal. 118, 255 (1989).

40. van der Wiele, K., Geerts, J. W. M. H., van Kasteren, J. M. N., in "Methane Conversion by Oxidative Processes" (E. E. Wolf, Ed.), p. 259. van Nostrand Reinhold, New York, 1992.

41. Nakamura, M., Yanagibashi, H., Mitsuhashi, H., and Takezawa, N., Bull. Chem. Soc. Jpn. 66, 2467 (1993).

42. Peng, X. D., Richards, D. A., and Stair, P. S., J. Catal. 121, 99 (1990).

43. Winter, E. R. S., J. Chem. Soc. (A), 2889 (1968).

44. Winter, E. R. S., J. Chem. Soc. (A), 1832 (1969).

45. Weast, R. C., "Handbook of Chemistry and Physics." CRC Press Inc., Boca Raton, FL, 1987.

46. Sinev, M. Y., Bychkov, V. Y., Korchak, V. N., Aptekar, E. L., and Krylov, O. V., Kinet. Catal. 30, 6, 1236 (1989).

47. Larkins, F. P., and Nordin, M. R., in "Methane Conversion" (D. M.
Bibby, C. D. Chang, R. F. Howe, and S. Yurchak, Eds.), p. 409. Elsevier Science, Amsterdam, 1988.

48. Yingli, B., Kaiji, Z., Yutao, J., Chiwen, T., and Xiangguong, Y., Appl. Catal. 39, 185 (1985).

49. Bartsch, S., Falkowski, J., and Hofmann, H., Catal. Today 4, 421 (1989).

50. Lacey, J. B., Abraham, M. M., Boldu, J. L., Chen, Y., Narayan, C. J., and Tohver, H. T., Phys. Rev. B 18, 8, 4136 (1978).

51. Bychkov, V. Y., Sinev, M. Y., Korchak, V. N., Aptekar, E. L., and Krylov, O. V., Kinet. Catal. 30, 5, 989 (1989).

52. Amorebieta, V. T., and Colussi, A. J., J. Phys. Chem. 92, 4576 (1988).

53. Robinson, P. J., and Holbrook, K. A., "Unimolecular Reactions." Wiley Interscience, London, 1972.

54. Chen, Q., Couwenberg, P. M., and Marin, G. B., A.I.Ch.E. J. 40, 3, 521 (1994).

55. Bytyn, W., and Baerns, M., Appl. Catal. 28, 199 (1986).

56. Chen, Q., Couwenberg, P. M., and Marin, G. B., Catal. Today 21, 309 (1994). 